\title{
CONCENTRAÇÃO DE MACRONUTRIENTES E SÓDIO EM GRAMÍNEAS CULTIVADAS EM SACS NO NORTE DE MINAS GERAIS
}

\author{
Rodrigo Nogueira Martins ${ }^{1}$ \\ Viktor Kayro Souza Santos ${ }^{2}$ \\ Ana Paula Ferreira Colares ${ }^{3}$ \\ Victória Viana Silva ${ }^{4}$ \\ Danilo Pereira Ribeiro ${ }^{5}$
}

Resumo: O presente trabalho foi realizado com o objetivo de avaliar a remoção de nutrientes e sódio pelas gramíneas Tifton-85, Paspalum vaginatum e Brachiaria mutica cultivados em Sistemas Alagados Construídos (SACs) tratando efluente da suinocultura. O experimento foi composto por três SACs de fluxo subsuperficial preenchidos com brita zero, tendo, cada um, $10 \mathrm{~m}$ de comprimento, 1,0 m de largura e 0,25 $m$ de profundidade. Cultivou-se uma espécie de gramínea por SAC. As plantas foram podadas a cada 30 dias para a coleta de amostras de tecido vegetal. Na análise dos 30 dias após a poda de uniformização, a gramínea Brachiaria mutica apresentou a maior concentração média de $N, K$ e Na, sendo 2,93, 4,4 e 0,41 dag $\mathrm{kg}^{-1}$, respectivamente, enquanto que, a gramínea Paspalum vaginatum aos 120 dias se sobressaiu na remoção de nutrientes, apresentando as maiores concentrações de N, P e K com médias de 2,94, 0,23 e 4,25 dag $\mathrm{kg}^{-1}$.

Palavras-chave: Suinocultura; Águas Residuárias; Sistemas Alagados Construídos.

\footnotetext{
${ }^{1}$ Engenharia Agrícola e Ambiental / Instituto Federal do Norte de Minas Gerais - IFNMG Campus Januária. Brasil. E-mail: Rodrigonmartins@hotmail.com.

2 Engenharia Agrícola e Ambiental / Instituto Federal do Norte de Minas Gerais - IFNMG Campus Januária. Brasil. E-mail: viktorpel@hotmail.com.

3 Engenharia Agrícola e Ambiental / Instituto Federal do Norte de Minas Gerais - IFNMG Campus Januária. Brasil. E-mail: anapaula.colares@hotmail.com.

${ }^{4}$ Engenharia Agrícola e Ambiental / Instituto Federal do Norte de Minas Gerais - IFNMG Campus Januária. Brasil. E-mail: victoria.viana.s@gmail.com.

5 Dsc. Engenharia Agrícola / Instituto Federal do Norte de Minas Gerais - IFNMG Campus Januária. Brasil. Email: danilo.ribeiro@ifnmg.edu.br.
} 